Check for updates

Cite this: RSC Adv., 2018, 8, 36400

\title{
A multifunctional microporous metal-organic framework: efficient adsorption of iodine and column-chromatographic dye separation $\dagger$
}

\author{
Chan Yao, ${ }^{a}$ Wei Wang, ${ }^{\text {a }}$ Shu-Ran Zhang, ${ }^{a}$ Hui-Ying Li, ${ }^{a}$ Yan-Hong Xu, (D) *ab \\ Zhong-Min Su (D) ${ }^{c}$ and Guang-Bo Che (DD *a
}

\begin{abstract}
In this work, a multifunctional microporous metal-organic framework (MOF), [Cd(ABTC) $\left.\left(\mathrm{H}_{2} \mathrm{O}\right)_{2}(\mathrm{DMA})\right]$. 4DMA (JLNU-4; JLNU = Jilin Normal University; $\mathrm{H}_{4}$ ABTC = 3,3',5,5'-azobenzenetetracarboxylic acid), has been synthesized based on the ligand $\mathrm{H}_{4}$ ABTC under solvothermal conditions. JLNU-4 shows excellent uptake of iodine both in solution and in the vapor phase, owing to the existence of a microporous structure in JLNU-4. The adsorption kinetics during the process of iodine adsorption were analyzed via a series of qualitative and quantitative analyses, such as the Langmuir and Freündlich adsorption isotherms. In addition, according to UV/vis spectroscopy analysis and the colour variance of JLNU-4, the relatively small sized dye methylene blue (MB) could be efficiently adsorbed by JLNU-4, through size-exclusion effects. Particularly, JLNU-4 can serve as a column-chromatographic filler for the separation of dye molecules. Therefore, JLNU-4 is a multifunctional microporous MOF for iodine

adsorption and column-chromatographic dye separation.
\end{abstract}

Received 31st May 2018

Accepted 15th October 2018

DOI: $10.1039 / \mathrm{c} 8 \mathrm{ra04648d}$

rsc.li/rsc-advances

\section{Introduction}

The release of hazardous chemicals is continually growing due to the rapid development of modern society and technological progress, with examples including nuclear waste, toxic heavy metal ions, organic dye molecules, and so on, which have brought significant threats to human and animal health. Although the demand for efficient and non-carbon-emitting nuclear energy is growing rapidly, an urgent issue of safety concern relating to nuclear power production is the appropriate approach to the disposal of waste products generated from the nuclear fission of uranium. ${ }^{1}$ In particular, radioactive iodine $\left(\mathrm{I}_{2}\right.$ containing ${ }^{129} \mathrm{I}$ and/or ${ }^{131} \mathrm{I}$ ), as the main component of waste streams, has attracted considerable attention because it could cause severe tissue damage and cancer to humans through the respiratory system via both beta and gamma radiation. ${ }^{2}$ It can

\footnotetext{
${ }^{a}$ Key Laboratory of Preparation and Applications of Environmental Friendly Materials, Jilin Normal University, Ministry of Education, Changchun 130103, Jilin, People's Republic of China. E-mail: xuyh198@163.com

${ }^{b}$ Key Laboratory of Functional Materials Physics and Chemistry of the Ministry of Education, Jilin Normal University, Siping 136000, Jilin, People's Republic of China

'Institute of Functional Material Chemistry, Faculty of Chemistry, Northeast Normal University, Changchun, 130024, Jilin, People's Republic of China

$\dagger$ Electronic supplementary information (ESI) available: IR, TGA, PXRD, $\mathrm{N}_{2}$ gas-sorption isotherm, pore size distribution, iodine adsorption kinetic, Langmuir and Freündlich adsorption isotherm, XPS and UV/vis spectra data, and additional figures and tables for JLNU-4. CCDC 1588369. For ESI and crystallographic data in CIF or other electronic format see DOI: $10.1039 / \mathrm{c} 8 \mathrm{ra0} 04648 \mathrm{~d}$
}

disperse rapidly in air and contaminate liquid as well as solid waste-processing systems. ${ }^{3}$ Additionally, the radioactive half-life is 8 days for ${ }^{129} \mathrm{I}$ and as long as $1.57 \times 10^{7}$ years for ${ }^{131} \mathrm{I}$, which can be incorporated into the human metabolic system. ${ }^{4}$ Therefore, the design of stable and highly effective materials for the capture and storage of radiological iodine has become a critical issue to be addressed. In general, inorganic composite adsorbents, for instance silver-based zeolites or aerogels, have been utilized for radioactive iodine capture. ${ }^{5}$ However, their limited available surface areas result in low uptake capacities for iodine. Besides, the high cost and adverse environmental impact of silver are the main disadvantages of silver-based zeolites or aerogels, which hinder their utilization and development. It remains a labor-intensive endeavor to synthesize porous materials with more efficient, less costly materials that have steady high-iodine trapping abilities for iodine capture in the gas phase and liquid phase.

Given the growing interest in exploring novel porous materials towards the effective capture and storage of iodine, various porous adsorbents, including inorganic materials, ${ }^{6}$ conjugated microporous polymers (CMPs), ${ }^{7}$ porous aromatic frameworks (PAFs), ${ }^{8}$ nanocomposites, ${ }^{9} \quad$ covalent organic frameworks $(\mathrm{COFs}),{ }^{10}$ and crystalline metal-organic frameworks (MOFs), ${ }^{11}$ have recently been constructed from well-functionalized organic building blocks for iodine capture. Among these porous materials, research into MOFs has been very fruitful, mainly because of their high specific surface areas, adjustable pore structures, regular pore shapes, and unique architectures and functionalities. ${ }^{12}$ Furthermore, the combination of 
appropriate organic ligands with varied geometries and functional metal ions or clusters could result in the rational design of MOFs with high porosities, tunable pore structures and desirable surface binding sites for the capture of iodine. ${ }^{13}$ Currently, Nenoff, Walton and their co-workers have demonstrated that HKUST-1, ${ }^{14}$ ZIF-8, ${ }^{2 c, 15}$ and MIL-53(Al) ${ }^{\mathbf{1 6}}$ can adsorb iodine with varying capacities, reversibilities and stabilities. Nevertheless, there are limits to MOF materials with high iodine uptake capacities. The influences on the iodine adsorption capacity involve not only the pore size, but also effective sorption sites, binding interactions of iodine within the cavity of MOFs, and the effects of iodine-iodine interactions, which may form polyiodide anions. ${ }^{17}$ Owing to the large molecular mass of adsorbed iodine, the pores of MOFs would be highly disordered after iodine adsorption, and iodine tends to have a high activation barrier for diffusion in host structures. ${ }^{18}$ As a result, it is vital to analyze the adsorption kinetics of iodine during the adsorption process. Nowadays, it is still a great challenge to synthesize MOFs with high iodine uptake capacity, and where possible to make clear the nature of the host-iodine and iodineiodine interaction(s) within MOF pores at a molecular level.

The porous structures of MOFs also inspire us to continuously explore their application in other fields as an excellent platform for host-guest chemistry, for example, the adsorption and separation of dye molecules. It has been extensively recognized that organic dyes have been widely used in many industrial fields, such as paper-making, printing, plastics, textiles, pharmaceuticals, and so on. ${ }^{19}$ But their toxicity and even carcinogenicity have posed a huge threat to the aqueous environment and human health, which cannot be ignored. ${ }^{20}$ In the meantime, most dyes are difficult to degrade because of their stability to light and oxidants. In this regard, low-cost and eco-friendly technology for the adsorption and separation of dyes is urgently required, which is more competitive than some other methods. Recently, MOFs have been applied in adsorbing or separating dye molecules, which usually consist of two types of process. (i) Dye removal depending on the size-exclusion effect, in other words, the kind of dyes to be absorbed relies on the pore size of the MOF. ${ }^{21}$ Sun et al. have synthesized two Cd-tib-carboxylate (tib =1,3,5-tris(1-imidazolyl)benzene) MOFs under solvothermal conditions, which could selectively adsorb methyl orange molecules. ${ }^{22}$ Lan and co-workers have reported a series of mesoporous MOFs with tailored pore sizes, which can incorporate a dye with a smaller size than that of a MOF pore, followed by column-chromatographic separation for large dye molecules. ${ }^{23}$ (ii) Charged MOFs adsorb dyes with opposite charges based on ionic exchange and electrostatic interactions. ${ }^{24}$ Shi et al. have prepared negatively charged uranyl-MOFs for selectively removing positively charged organic dyes over negatively charged and neutral ones. ${ }^{25}$ In a previous work, we also reported a microporous anionic MOF, $\left[\mathrm{Zn}(\mathrm{ABTC})_{0.5}\left(\mathrm{NO}_{3}\right)\right]$ $\left[\left(\mathrm{CH}_{3}\right)_{2} \mathrm{NH}_{2}\right] \cdot \mathrm{DMA} \cdot 3 \mathrm{H}_{2} \mathrm{O} \quad\left(\mathrm{H}_{4} \mathrm{ABTC}=3,3^{\prime}, 5,5^{\prime}\right.$-azobenzenetetracarboxylic acid; DMA $=N, N$-dimethylacetamide), which could efficiently adsorb cationic dyes and serve as a columnchromatographic filler for the separation of dye molecules. ${ }^{26}$

As a continuation of our work, we obtain a 3D microporous MOF, [Cd(ABTC) $\left.\left(\mathrm{H}_{2} \mathrm{O}\right)_{2}(\mathrm{DMA})\right] \cdot 4 \mathrm{DMA}(\mathbf{J L N U}-4)$, synthesized via the solvothermal reaction of $\mathrm{Cd}\left(\mathrm{NO}_{3}\right)_{2} \cdot 4 \mathrm{H}_{2} \mathrm{O}$ and $\mathrm{H}_{4} \mathrm{ABTC}$. It is shown that neutral iodine can be trapped in the vapor and solution phase by JLNU-4. In addition, we have carried out a series of qualitative and quantitative analyses during the process of $\mathrm{I}_{2}$ adsorption. Meanwhile, JLNU-4 can selectively adsorb the dye molecule methylene blue (MB) via size-exclusion effects, due to the microporous structure, which makes it an excellent candidate for column-chromatographic dye adsorption and separation.

\section{Experimental}

\section{Materials and measurements}

Chemicals were obtained from commercial sources and were used without further purification. Fourier transform infrared (FT-IR) spectra were recorded over the range $4000-400 \mathrm{~cm}^{-1}$ on a Perkin-Elmer FT-IR-Frontier infrared spectrometer using $\mathrm{KBr}$ pellets. Elemental microanalyses $(\mathrm{C}, \mathrm{H}$, and $\mathrm{N}$ ) were performed on a EuroEA-3000 elemental analyzer. Thermogravimetric analysis (TGA) was performed on a Q5000IR analyser (TA Instruments) with an automated vertical overhead thermobalance heated from 40 to $1000{ }^{\circ} \mathrm{C}$ at a ramp rate of $5{ }^{\circ} \mathrm{C} \mathrm{min}{ }^{-1}$ under a nitrogen atmosphere. Powder X-ray diffraction (PXRD) was performed on a Rigaku model RINT Ultima III diffractometer over the range of $5-60^{\circ}$ at $293 \mathrm{~K}$ by depositing powder on a glass substrate. The solution UV/vis adsorption spectra were recorded using Shimadzu UV-3600 apparatus. X-ray photoelectron spectra (XPS) were recorded on an ESCALAB250Xi electron spectrometer (Thermo Fisher Scientific Inc., Waltham, MA, USA). Nitrogen sorption isotherms were measured at $77 \mathrm{~K}$ with an ASIQ (iQ-2) volumetric adsorption analyzer. Before gas adsorption measurements, the sample was immersed in methanol for $24 \mathrm{~h}$, and the extract was decanted. Fresh methanol was subsequently added, and the crystals were left for an additional $24 \mathrm{~h}$ to remove nonvolatile solvates. The sample was collected via decanting and treated with dichloromethane similarly to remove methanol solvates. After the removal of dichloromethane via decanting, the sample was activated through drying under a dynamic vacuum at room temperature overnight. Before measurements, the sample was dried again by using the 'outgas' function of the surface area analyzer for $12 \mathrm{~h}$ at room temperature. The Brunauer-Emmett-Teller (BET) method was utilized to calculate the specific surface areas and pore volumes. Non-local density functional theory (NLDFT) was applied for estimations of pore size and pore size distribution. Energy dispersive spectroscopy (EDS) images were obtained on a JEOL model JSM-6700 operating at an accelerating voltage of $5.0 \mathrm{kV}$. The samples were prepared for EDS via drop-casting a tetrahydrofuran suspension onto a mica substrate and then coating with gold.

\section{Synthesis of [Cd(ABTC)( $\left.\left.\mathrm{H}_{2} \mathrm{O}\right)_{2}(\mathrm{DMA})\right] \cdot$ 4DMA (JLNU-4)}

A mixture of $\mathrm{H}_{4} \mathrm{ABTC}(0.01 \mathrm{~g}, 0.03 \mathrm{mmol}), \mathrm{Cd}\left(\mathrm{NO}_{3}\right)_{2} \cdot 4 \mathrm{H}_{2} \mathrm{O}$ (0.20 g, $0.65 \mathrm{mmol})$, DMA ( $4 \mathrm{~mL})$ and $\mathrm{CH}_{3} \mathrm{OH}(4 \mathrm{~mL})$ was sealed in a Teflon-lined stainless steel container and heated in an autoclave at $100{ }^{\circ} \mathrm{C}$ for $96 \mathrm{~h}$. After the autoclave was cooled to 
room temperature, yellow crystals were obtained and isolated via washing with DMA and drying at room temperature; yield: $65 \%$ based on $\mathrm{H}_{4} \mathrm{ABTC}$. Elemental microanalysis for $\mathrm{C}_{36} \mathrm{H}_{51} \mathrm{~N}_{7} \mathrm{O}_{15} \mathrm{Cd}_{2}$ : calculated (\%): C, 41.31; H, 4.91; N, 9.37; found (\%): C, 41.25; H, 4.98; N, 9.46. IR ( $\mathrm{cm}^{-1}$, ESI Fig. S1a †): $3082(\mathrm{~m}), 2933(\mathrm{~m}), 1642(\mathrm{~s}), 1507(\mathrm{~s}), 1443(\mathrm{~m}), 1401(\mathrm{~s}), 1366$ (s), $1260(\mathrm{~s}), 1187(\mathrm{~m}), 1019(\mathrm{~m}), 971(\mathrm{w}), 787(\mathrm{~s}), 724(\mathrm{w}), 590(\mathrm{w})$, $477(\mathrm{w})$.

\section{X-ray crystallography}

Single crystal X-ray diffraction data in this work were recorded on a Bruker APEXII CCD diffractometer with graphitemonochromated Mo $K_{\alpha}$ radiation $(\lambda=0.71069 \AA)$ at $293 \mathrm{~K}$. Absorption corrections were applied using a multi-scan technique. All structures were solved via the direct method of SHELXS-97 (ref. 27a) and refined via full-matrix least-squares techniques using the SHELXL-97 program $^{27 b}$ within WINGX. ${ }^{27 c}$ Non-hydrogen atoms were refined with anisotropic temperature parameters. The SQUEEZE program implemented in PLATON was used to remove electron densities from the compounds. Thus, all electron densities from free solvent molecules have been "squeezed" out. The CCDC number is 1588369. Detailed crystallographic data and structure refinement parameters are summarized in Table S1 (ESI†).

\section{Results and discussion}

The yellow block crystals of JLNU-4 have been obtained via the solvothermal reaction of $\mathrm{Cd}\left(\mathrm{NO}_{3}\right)_{2} \cdot 4 \mathrm{H}_{2} \mathrm{O}$ and $\mathrm{H}_{4} \mathrm{ABTC}$ in DMA. The formula of JLNU-4 is $\left[\mathrm{Cd}(\mathrm{ABTC})\left(\mathrm{H}_{2} \mathrm{O}\right)_{2}(\mathrm{DMA})\right] \cdot 4 \mathrm{DMA}$, taking single-crystal X-ray diffraction studies, TGA (Fig. S2, ESI $\dagger$ ) and elemental analysis into consideration. Single-crystal X-ray diffraction studies reveal that JLNU-4 crystallizes in the monoclinic space group $P 2_{1} / c$ (Table S1, ESI $\dagger$ ). The crystallographically independent unit contains two $\mathrm{Cd}^{2+}$ ions, a type of ligand fragment, two coordinated $\mathrm{H}_{2} \mathrm{O}$ molecules and one coordinated DMA molecule (Fig. 1a). The Cd1 atom is sevencoordinate through seven oxygen atoms from four $\mathrm{H}_{4} \mathrm{ABTC}$ ligands. The $\mathrm{Cd} 2$ atom is six-coordinate through three oxygen atoms from three $\mathrm{H}_{4} \mathrm{ABTC}$ ligands, one oxygen atom from a coordinated DMA molecule and two oxygen atoms from two coordinated $\mathrm{H}_{2} \mathrm{O}$ molecules. The two kinds of $\mathrm{Cd}$ atom are linked by three carboxylate groups to form a binuclear $\left[\mathrm{Cd}_{2}(-\right.$ $\left.\mathrm{COO})_{4}\left(\mathrm{H}_{2} \mathrm{O}\right)_{2}(\mathrm{DMA})\right]$ cluster (Fig. S3, ESI $\dagger$ ). The $\mathrm{Cd}-\mathrm{O}$ bond lengths are all within the normal ranges (Table S2, ESI $\dagger$ ). The adjacent $\left[\mathrm{Cd}_{2}(\mathrm{COO})_{4}\left(\mathrm{H}_{2} \mathrm{O}\right)_{2}(\mathrm{DMA})\right]$ clusters are connected to each other by the ligand, giving rise to an infinite 3D framework with microporous characteristics (Fig. $1 \mathrm{~b}$ and S4, ESI $\dagger$ ). The approximate sizes of the channels are $10.4 \times 8.7 \AA^{2}$ and $7.8 \times$ $7.5 \AA^{2}$ along the $b$ axis. From topological analysis, each $\left[\mathrm{Cd}_{2}(-\right.$ $\left.\mathrm{COO})_{4}\left(\mathrm{H}_{2} \mathrm{O}\right)_{2}(\mathrm{DMA})\right]$ cluster is considered as a 4 -connected node and, in turn, each $\mathrm{H}_{4} \mathrm{ABTC}$ ligand unit also acts as a 4-connected node (Fig. S5, ESI $\dagger$ ), leading to a $(4,4)$-connected 3D network with pts topology (Schläfli symbol: $\left(4^{2} \cdot 8^{4}\right)$; Fig. 1c-e). ${ }^{28}$ Although the ligand and topological structure are the same as in Zhu's work, ${ }^{29}$ the structural details, such as the space group, the (a)

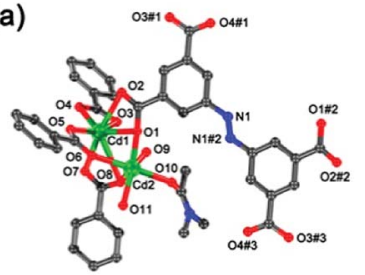

(c)

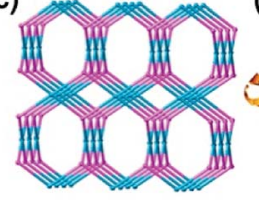

(d)

(d) (b)

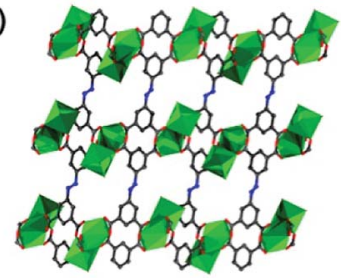

(e)
Fig. 1 (a) The coordination environments of $\mathrm{Cd}$ atoms in JLNU-4. Symmetry code: \#1: $-x+1, y+0.5,-z+0.5$; \#2: $-x+1,-y+1,-z$; \#3: $x,-y+0.5, z-0.5$. (b) Infinite 3D framework with channels viewed along the $b$ axis. (c) Ball-and-stick and (d) polyhedral views of the $(4,4)$ connected topology network in JLNU-4. (e) The $(4,4)$-connected augmented net in the form of natural tiling. All hydrogen atoms are omitted for clarity.

coordination environment of the $\mathrm{Cd}$ atoms, the pore size, and the synthetic method are all distinguishing.

The PXRD patterns of both simulated and as-synthesized JLNU-4 match well in key positions, thus indicating that it possesses good phase purity (Fig. S6, ESI†). The PXRD pattern of activated JLNU-4 is almost identical with that of the assynthesized one, as illustrated in Fig. S6 in the ESI, $\dagger$ implying that the basic 3D framework is retained. The calculated free volume in fully desolvated JLNU-4 is $56.3 \%$ from PLATON..$^{30} \mathrm{~N}_{2}$ sorption studies demonstrate the existence of permanent porosity in JLNU-4. The Brunauer-Emmett-Teller (BET) surface area of JLNU-4 is estimated to be $64 \mathrm{~m}^{2} \mathrm{~g}^{-1}$ (Fig. S7a, ESI $\dagger$ ). The pore size distribution plot has been drawn by employing the NLDFT method, as shown in Fig. S7b (ESI $\dagger$ ), representing that micropores exist in JLNU-4.

Considering the microporous properties of JLNU-4, its capacity towards molecular iodine capture both in solvent and vapor phases was explored. When fresh samples of JLNU-4 (20 $\mathrm{mg}$ ) were immersed in a hexane $(3 \mathrm{~mL})$ solution of iodine $(4 \mathrm{mg}$ $\left.\mathrm{mL}^{-1}\right),{ }^{31-43}$ the colour of the solution gradually faded from dark purple to light purple with the extension of time (Fig. 2a, top). At the same time, the colour of the crystals changed from yellow to brown to black over $24 \mathrm{~h}$ (Fig. 2b). To further qualitatively investigate the process of iodine capture in JLNU-4, UV/vis spectra were monitored at room temperature. The intensities of the UV/vis adsorption spectra decreased with prolonged time (Fig. 2c).

Subsequently, quantitative analysis was carried out to gain a deeper insight into the adsorption kinetics of iodine. At an early stage, the adsorption capacity increased quickly with the prolongation of contact time and tended to increase gradually after $10 \mathrm{~h}$, illustrating that the adsorption kinetics were related to contact time (Fig. S8 and S9, ESI†). The removal efficiency was raised to as much as $92.9 \%$. The adsorption kinetics were analysed through the frequently used pseudo-first-order and pseudo-second-order kinetic models. ${ }^{44}$ The equation of the 

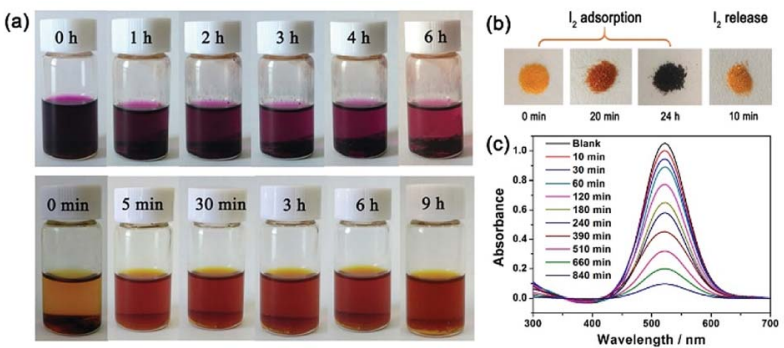

Fig. 2 (a) Photographs of JLNU-4 during the iodine adsorption process in hexane solution (top) and the iodine release process in ethanol solution (bottom). (b) Photographs showing the visual color change of JLNU-4 during iodine adsorption and release. (c) UV/vis spectra upon immersion of JLNU-4 $(20 \mathrm{mg})$ in a hexane solution of iodine $\left(0.4 \mathrm{mg} \mathrm{mL}^{-1}\right)$.

linear form for the pseudo-first-order kinetic model was eqn (1) as follows, where $Q_{t}$ and $Q_{\mathrm{e}}$ represent the mass percent of iodine adsorbed at time $t$ and equilibrium (\%), and $k_{1}$ is the rate constant of the adsorption process $\left(\mathrm{h}^{-1}\right)$. Eqn (2) was the linear form of the pseudo-second-order kinetic model, in which $Q_{t}$ and $Q_{\mathrm{e}}$ were the mass percentages of iodine adsorbed at time $t$ and equilibrium (\%), and $k_{2}$ was the pseudo-second-order rate constant of the adsorption process $\left(\mathrm{h}^{-1}\right)$. According to the simulation analysis, we found that the adsorption data fitted well to the pseudo-second-order kinetic model with a good linear correlation coefficient $\left(R^{2}\right)$ value of 0.9837 (Table S3, ESI $\dagger$ ). This also proved that the pseudo-second-order kinetic model governed the process of iodine adsorption.

$$
\begin{gathered}
\ln \left(Q_{\mathrm{e}}-Q_{t}\right)=\ln Q_{\mathrm{e}}-k_{1} t \\
\frac{t}{Q_{t}}=\frac{1}{k_{2} Q_{\mathrm{e}}{ }^{2}}+\frac{t}{Q_{\mathrm{e}}}
\end{gathered}
$$

Besides, the adsorption isotherms, Langmuir or Freündlich, could determine the saturated iodine adsorption capacity of JLNU-4. The Langmuir and Freündlich adsorption isotherm models are given in eqn (3) and (4), respectively. In the equations, $k_{\mathrm{L}}\left(\mathrm{mg}^{-1}\right)$ and $Q_{\mathrm{m}}\left(\mathrm{mg} \mathrm{g}^{-1}\right)$ are the Langmuir isotherm constants, $k_{\mathrm{F}}\left(\mathrm{mg}^{-1}\right)$ and $n$ are the Freündlich isotherm constants, $C_{\mathrm{e}}$ is the concentration at equilibrium $\left(\mathrm{mg} \mathrm{mL}^{-1}\right)$, and $Q_{\mathrm{e}}$ is the amount of iodine adsorbed at equilibrium (mg $\mathrm{g}^{-1}$ ). There were two different adsorption stages in the plot of equilibrium concentration versus quantity of adsorbed iodine at equilibrium (Fig. S10 and S11, ESI†). In the first instance, the plots were nearly linear at low concentrations, that is to say the equilibrium uptake increased linearly with the increase in iodine solution concentration. After that, the adsorption reached the maximum value and the adsorption process became independent of the concentration. The Langmuir adsorption isotherm could better judge the saturated iodine adsorption capacity with a good linear correlation coefficient $\left(R^{2}\right)$ value of 0.98043 from the simulation analysis (Table S4, ESI†). The saturated iodine adsorption capacity of JLNU-4 in the solvent phase could reach $680 \mathrm{mg} \mathrm{g}^{-1}$, as depicted in Fig. S10 $\dagger$ in the ESI. $\dagger$ Moreover, the release of the trapped iodine molecules into JLNU-4 occured very soon via the immersion of the iodine-loaded samples in ethanol. The color of the solvent changed from colorless to dark brown when the iodine-loaded samples were immersed in ethanol (Fig. 2a, bottom), suggesting that iodine molecules were released from JLNU-4. The color of the crystals almost recovered its original yellow after the initial ten minutes of the release process (Fig. 2b). There were no major changes to either the external appearance or the XRPD patterns after immersing JLNU-4 in hexane solution, even after the process of iodine adsorption and release (Fig. S12, ESI†). This confirmed the reversibility of iodine adsorption and release, and the high stability of the host, JLNU-4.

$$
\begin{gathered}
Q_{\mathrm{e}}=\frac{Q_{\mathrm{m}} k_{\mathrm{L}} C_{\mathrm{e}}}{1+k_{\mathrm{L}} C_{\mathrm{e}}} \\
Q_{\mathrm{e}}=k_{\mathrm{F}} C_{\mathrm{e}^{n}}^{\frac{1}{n}}
\end{gathered}
$$

It is widely acknowledged that iodine is volatile, thus iodine adsorption in the vapor phase is critically important. JLNU-4 (30 $\mathrm{mg}$ ) was exposed to nonradioactive iodine vapor in a sealed vessel at $350 \mathrm{~K}$ and under ambient pressure; these are typical fuel reprocessing conditions. ${ }^{45-50}$ During the adsorption process, gravimetric measurements were performed at time intervals (Table S5, ESI $†$ ). The maximum iodine uptake of JLNU4 reached saturation after $10 \mathrm{~h}$ (Fig. S13, ESI $\dagger$ ). The saturated iodine adsorption value was $64 \mathrm{wt} \%\left(636.7 \mathrm{mg} \mathrm{g}^{-1}\right)$. There was significant weight loss from 90 to $300{ }^{\circ} \mathrm{C}$ in the TGA of iodineloaded JLNU-4, which might be caused by the decomposition of iodine (Fig. S2, ESI $\dagger$ ). The XPS spectra of JLNU-4 after iodine adsorption in hexane solution and iodine vapor adsorption verified the existence of iodine, which meant that the adsorption took the form of physical adsorption (Fig. S14, ESI $\dagger$ ).

From an environmental point of view, removing dyes from effluents before discharging them into natural water bodies is extremely vital. Organic dyes, with a variety of colors and sizes, are a big group of organic molecules, which are frequently used in numerous manufacturing industries and subsequently cause various environmental problems. ${ }^{51}$ Motivated by the existing pores in JLNU-4, we selected several organic dyes with different molecular sizes for dye sorption on the basis of the sizeexclusion effect. There was no need for any further activation process compared with other reported MOFs for dye sorption. ${ }^{52}$ To measure whether JLNU-4 had the ability for dye molecule adsorption, we prepared fresh JLNU-4 to capture dyes in DMA. Crystals of JLNU-4 $(100 \mathrm{mg})$ were soaked in DMA solutions of a series of dyes $(10 \mathrm{~mL}, 1.0 \mathrm{mmol})$. A color change in JLNU-4 was clearly observed in methylene blue (MB) by the naked eye after soaking for about one hour (Fig. 3). As illustrated in the inset of Fig. 3, the uniform distribution of MB throughout JLNU-4 indicated that the organic dye molecules deeply penetrated into the pores instead of only being adsorbed on the external surface of JLNU-4..$^{53}$ This may be caused by $\pi-\pi *$ interactions between aromatic moieties of the frameworks and dyes. ${ }^{22}$ We have also measured the $\mathrm{N}_{2}$ gas-sorption for MB loaded JLNU-4 (Fig. S15, ESI $\dagger$ ). The adsorption capacity of MB loaded JLNU-4 


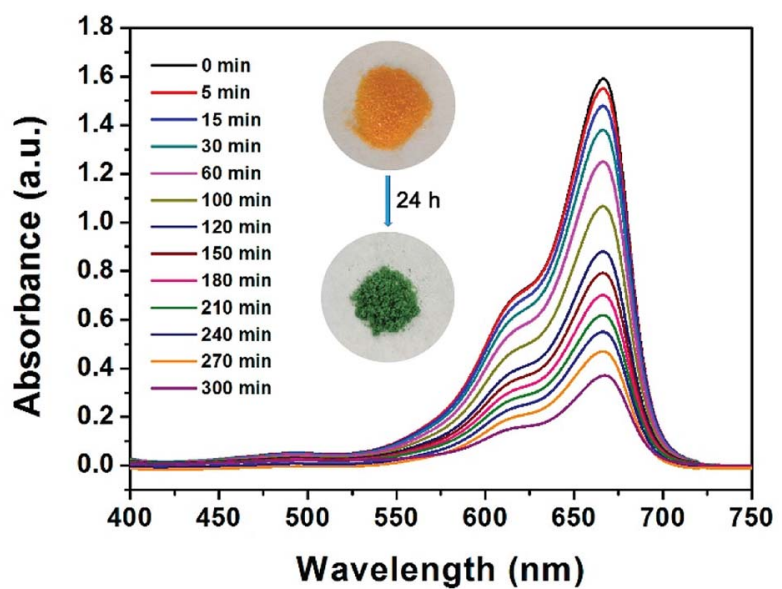

Fig. 3 UV/vis spectra of DMA solutions of MB with freshly prepared JLNU-4. Inset: photographs of the color change of crystals after immersion in a solution of MB for a period of time.

significantly decreased compared to JLNU-4 (Fig. S7a, ESI†). The obvious sorption hysteresis can be interpreted as arising from the network swelling or restricted access of adsorbate molecules through narrow pore openings. The BET surface area of MB loaded JLNU-4 is estimated to be $8.1 \mathrm{~m}^{2} \mathrm{~g}^{-1}$, which is also lower than that of JLNU-4 $\left(64 \mathrm{~m}^{2} \mathrm{~g}^{-1}\right)$. Therefore, MB has been adsorbed into the pores of JLNU-4. Owing to the microporous structure of JLNU-4, only the relatively small sized MB, in comparison to other dye molecules, could be adsorbed into the pores. The adsorption capabilities of JLNU-4 for MB were quantitatively determined through UV/vis spectroscopy analysis (Fig. 3). The concentration of MB in DMA observably decreased with the passage of time, which showed that JLNU-4 could completely and rapidly adsorb MB. At the same time, the PXRD patterns affirmed that JLNU-4 could remain stable after adsorbing MB in DMA (Fig. S16, ESI $\dagger$ ). Moreover, EDS data (Fig. S17, ESI $\dagger$ ) and XPS (Fig. S18, ESI $\dagger$ ) data testify the existence of chlorine atoms in MB loaded JLNU-4. Therefore, MB molecules were absorbed as a chloride salt.

Inspired by the dye adsorption properties of JLNU-4, we prepared a chromatography column filled with JLNU-4 and a mixture of $\mathrm{MB}$ and $\mathrm{CR}(1: 1,1.0 \mathrm{mmol}, \mathrm{CR}=$ congo red $)$ in DMA solution. The two dyes could be successfully separated via passing them through the MOF-filled column. As shown in Fig. 4(I), JLNU-4 filled the chromatography column made of a glass dropper. When the dye mixture of MB and CR naturally passed through the JLNU-4-filled column under gravity, it was clearly observed that the color of the column became dark green (Fig. 4(II)). Next, the pure DMA stream passed through the column several times. As we expected, the larger and unincorporated CR was rapidly transported through the column along with the DMA stream while the small-sized MB was captured inside the JLNU-4-filled column (Fig. 4(III-VII)). UV-vis spectra of the effluent as the dye mixture of MB and CR passed through the JLNU-4-filled chromatographic column reveal the successful separation of MB and CR (Fig. S19, ESI $\dagger$ ). The continuing decrease of the characteristic absorbance of MB reveals its successful incorporation, whereas the

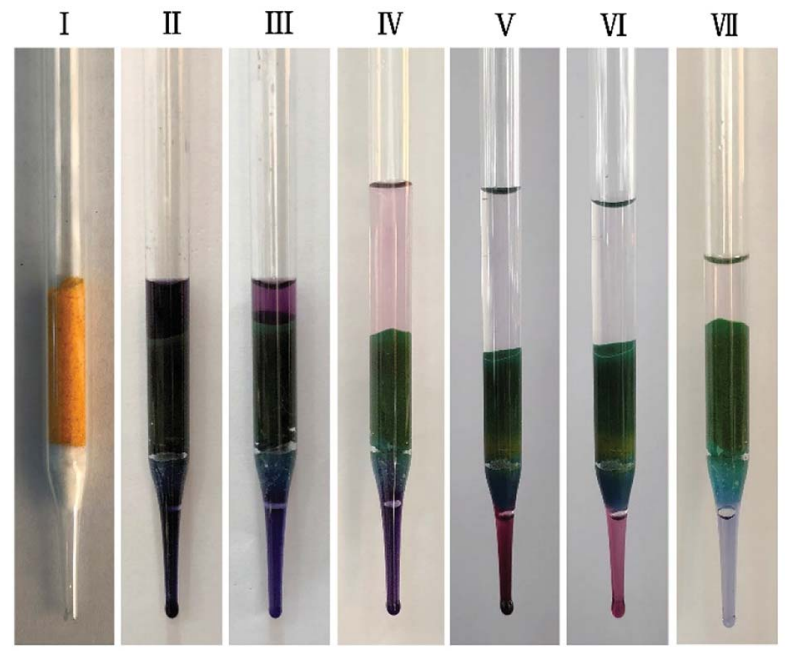

Fig. 4 Photographic records of the JLNU-4-filled column-chromatographic separation process for $M B$ and $C R$ dyes showing: (I) a JLNU-4-filled column, (II-VI) the separation process with the gradual color change, and (VII) complete separation with only MB adsorbed.

unchanged peak of BR suggests its exclusion by the MOF pores. Therefore, JLNU-4 could be used for dye separation via a combination of chromatography column and the sizeexclusion effect. This also demonstrated that MOFs with suitable pore sizes could be an outstanding selection for column-packing materials, which might be a substitute for traditional silica gels for size-dependent large molecule separation.

\section{Conclusions}

In summary, a 3D microporous MOF, JLNU-4, has been rationally designed and constructed via a solvothermal reaction. Bearing the microporous structure of JLNU-4 in mind, we carried out iodine adsorption experiments on JLNU-4. The results have proved that JLNU-4 could capture neutral iodine molecules in the solution phase as well as in the vapor phase. The saturated iodine adsorption capacity of JLNU-4 was $680 \mathrm{mg} \mathrm{g}^{-1}$ in the solvent phase. A series of qualitative and quantitative analyses were performed to analyze the adsorption kinetics in the process of iodine adsorption. Meanwhile, JLNU-4 can not only be used for the selective adsorption of MB but also can be applied as a column-chromatography filler for separating dye molecules. Therefore, JLNU-4 is a prominent and effective adsorbent for iodine adsorption and dye separation. This research has presented progressive evolution in the construction of MOF-based multifunctional materials. The exploration of more novel applications for multifunctional MOF materials is currently underway and will be useful under more realistic circumstances in the future.

\section{Conflicts of interest}

There are no conflicts to declare. 


\section{Acknowledgements}

The financial support of the National Natural Science Foundation of China (Grants no. 21501065), Changbai Mountain Scholars Program (Grants no. 2013073), the Science and Technology Program of Jilin Province (Grants no. 20160101319JC, 20180520159JH and 20180520152JH), the Science and Technology Plan Funds of Siping City, China (No. 2017092), and the Thirteenth Five-Year Program for Science and Technology of Education Department of Jilin Province (JJKH20180760KJ) is acknowledged.

\section{Notes and references}

1 G. Steinhauser, Environ. Sci. Technol., 2014, 48, 4649-4663.

2 (a) D. Shetty, J. Raya, D. S. Han, Z. Asfari, J.-C. Olsen and A. Trabolsi, Chem. Mater., 2017, 29, 8968-8972; (b) N. Yoshida and J. Kanda, Science, 2012, 336, 1115-1116; (c) D. F. Sava, M. A. Rodriguez, K. W. Chapman, P. J. Chupas, J. A. Greathouse, P. S. Crozier and T. M. Nenoff, J. Am. Chem. Soc., 2011, 133, 12398-12401; (d) W. J. Weber and F. P. Roberts, Nucl. Technol., 1983, 60, 178-198.

3 C. Pei, T. Ben, S. Xua and S. Qiu, J. Mater. Chem. A, 2014, 2, 7179-7187.

4 (a) G. Audi, O. Bersillon, J. Blachot and A. H. Wapstra, Nucl. Phys. A, 2003, 729, 3-128; (b) J. Wang, J. Luo, X. Luo, J. Zhao, D.-S. Li, G. Li, Q. S. Huo and Y. Liu, Cryst. Growth Des., 2015, 15, 915-920.

5 (a) K. W. Chapman, P. J. Chupas and T. M. Nenoff, J. Am. Chem. Soc., 2010, 132, 8897-8899; (b) K. S. Subrahmanyam, D. Sarma, C. D. Malliakas, K. Polychronopoulou, B. J. Riley, D. A. Pierce, J. Chun and M. G. Kanatzidis, Chem. Mater., 2015, 27, 2619-2626.

6 (a) T. Hertzsch, F. Budde, E. Weber and J. Hulliger, Angew. Chem., Int. Ed., 2002, 41, 2281-2284; (b) L. Mohanambe and S. Vasudevan, Inorg. Chem., 2004, 43, 6421-6425; (c) J. L. Krumhansl and T. M. Nenoff, Appl. Geochem., 2011, 26, 57-64.

7 (a) Y. Zhu, Y.-J. Ji, D.-G. Wang, Y. Zhang, H. Tang, X.-R. Jia, M. Song, G. Yu and G.-C. Kuang, J. Mater. Chem. A, 2017, 5, 6622-6629; (b) Y. Liao, J. Weber, B. M. Mills, Z. Ren and C. F. J. Faul, Macromolecules, 2016, 49, 6322-6333; (c) A. Sigen, Y. Zhang, Z. Li, H. Xia, M. Xue, X. Liu and Y. Mu, Chem. Commun., 2014, 50, 8495-8498; (d) T. Geng, Z. Zhua, W. Zhang and Y. Wang, J. Mater. Chem. A, 2017, 5, 76127617; (e) X. Qian, Z.-Q. Zhu, H.-X. Sun, F. Ren, P. Mu, W. Liang, L. Chen and A. Li, ACS Appl. Mater. Interfaces, 2016, 8, 21063-21069.

8 Z. Yan, Y. Yuan, Y. Tian, D. Zhang and G. Zhu, Angew. Chem., Int. Ed., 2015, 54, 12733-12737.

9 G. Massasso, M. Rodriguez-Castillo, J. Long, A. Grandjean, B. Onida, Y. Guari, Ch. Guerina and J. Larionova, J. Mater. Chem. A, 2015, 3, 179-188.

10 (a) Y. Lin, X. Jiang, S. T. Kim, S. B. Alahakoon, X. Hou, Z. Zhang, C. M. Thompson, R. A. Smaldone and C. Ke, J. Am. Chem. Soc., 2017, 139, 7172-7175; (b) A. P. Katsoulidis,
J. Q. He and M. G. Kanatzidis, Chem. Mater., 2012, 24, 1937-1943.

11 (a) D. Y. Lee, E.-K. Kim, N. K. Shrestha, D. W. Boukhvalov, J. K. Lee and S.-H. Han, ACS Appl. Mater. Interfaces, 2015, 7, 18501-18507; (b) F. Dai, W. Fan, X. Yuan, Z. Huang, Y. Wang, X. Xin, H. Lin, L. Zhang, R. Wang and D. Sun, Chem. Commun., 2017, 53, 5694-5697.

12 (a) H.-C. Zhou, J. R. Long and O. M. Yaghi, Chem. Rev., 2012, 112, 673-674; (b) S. Kitagawa, R. Kitaura and S. I. Noro, Angew. Chem., Int. Ed., 2004, 43, 2334-2375; (c) G. Férey, Chem. Soc. Rev., 2008, 37, 191-214.

13 (a) D. Zhao, D. J. Timmons, D. Yuan and H.-C. Zhou, Acc. Chem. Res., 2011, 44, 123-133; (b) W. Lu, Z. Wei, Z.-Y. Gu, T.-F. Liu, J. Park, J. Park, J. Tian, M. Zhang, Q. Zhang and T. Gentle III, Chem. Soc. Rev., 2014, 43, 5561-5593; (c) F. A. A. Paz, J. Klinowski, S. M. Vilela, J. P. Tome, J. A. Cavaleiro and J. Rocha, Chem. Soc. Rev., 2012, 41, 1088-1110; (d) A. Schoedel, M. Li, D. Li, M. O'Keeffe and O. M. Yaghi, Chem. Rev., 2016, 116, 12466-12535.

14 D. F. Sava, K. W. Chapman, M. A. Rodriguez, J. A. Greathouse, P. S. Crozier, H. Zhao, P. J. Chupas and T. M. Nenoff, Chem. Mater., 2013, 25, 2591-2596.

15 J. T. Hughes, D. F. Sava, T. M. Nenoff and A. Navrotsky, J. Am. Chem. Soc., 2013, 135, 16256-16259.

16 A. S. Munn, F. Millange, M. Frigoli, N. Guillou, C. Falaise, V. Stevenson, C. Volkringer, T. Loiseau, G. Cibin and R. I. Walton, CrystEngComm, 2016, 18, 8108-8114.

17 R.-X. Yao, X. Cui, X.-X. Jia, F.-Q. Zhang and X.-M. Zhang, Inorg. Chem., 2016, 55, 9270-9275.

18 X. Zhang, I. da Silva, H. G. W. Godfrey, S. K. Callear, S. A. Sapchenko, Y. Cheng, I. Vitórica-Yrezábal, M. D. Frogley, G. Cinque, C. C. Tang, C. Giacobbe, C. Dejoie, S. Rudić, A. J. Ramirez-Cuesta, M. A. Denecke, S. Yang and M. Schröder, J. Am. Chem. Soc., 2017, 139, 16289-16296.

19 (a) F.-Y. Yi, W. Zhu, S. Dang, J.-P. Li, D. Wu, Y.-H. Li and Z.-M. Sun, Chem. Commun., 2015, 51, 3336-3339; (b) C.-F. Zhang, L.-G. Qiu, F. Ke, Y.-J. Zhu, Y.-P. Yuan, G.-S. Xu and X. Jiang, J. Mater. Chem. A, 2013, 1, 14329-14334.

20 (a) W. Fan, W. Gao, C. Zhang, W. W. Tjiu, J. Pan and T. Liu, J. Mater. Chem., 2012, 22, 25108-25115; (b) A. A. Adeyemo, I. O. Adeoye and O. S. Bello, Toxicol. Environ. Chem., 2012, 94, 1846-1863.

21 (a) B.-X. Dong, M. Tang, W.-L. Liu, Y.-C. Wu, Y.-M. Pan, F.-Y. Bu and Y.-L. Teng, Cryst. Growth Des., 2016, 16, 63636370; (b) L.-H. Cao, Y.-L. Wei, C. Ji, M.-L. Ma, S.-Q. Zang and T. C. W. Mak, Chem.-Asian J., 2014, 9, 3094-3098; (c) Y. Zhu, Y.-M. Wang, S.-Y. Zhao, P. Liu, C. Wei, Y.-L. Wu, C.-K. Xia and J.-M. Xie, Inorg. Chem., 2014, 53, 7692-7699.

22 Y.-L. Li, Y. Zhao, P. Wang, Y.-S. Kang, Q. Liu, X.-D. Zhang and W.-Y. Sun, Inorg. Chem., 2016, 55, 11821-11830.

23 Y.-Q. Lan, H.-L. Jiang, S.-L. Li and Q. Xu, Adv. Mater., 2011, 23, 5015-5020.

24 (a) Y. Shen, C.-C. Fan, Y.-Z. Wei, J. Du, H.-B. Zhu and Y. Zhao, Dalton Trans., 2016, 45, 10909-10915; (b) Z. Zhu, Y.-L. Bai, L. Zhang, D. Sun, J. Fang and S. Zhu, Chem. Commun., 2014, 50, 14674-14677; (c) Y.-X. Tan, Y. Zhang, Y.-P. He, 
Y.-J. Zheng and J. Zhang, Inorg. Chem., 2014, 53, 1297312976; (d) D.-M. Chen, W. Shi and P. Cheng, Chem. Commun., 2015, 51, 370-372; (e) J. Li, H.-R. Fu, J. Zhang, L.-S. Zheng and J. Tao, Inorg. Chem., 2015, 54, 3093-3095;

(f) C.-Y. Sun, X.-L. Wang, C. Qin, J.-L. Jin, Z.-M. Su, P. Huang and K.-Z. Shao, Chem.-Eur. J., 2013, 19, 363-3645.

25 K.-Q. Hu, X. Jiang, C.-Z. Wang, L. Mei, Z.-N. Xie, W.-Q. Tao, X.-L. Zhang, Z.-F. Chai and W.-Q. Shi, Chem.-Eur. J., 2017, 23, 529-532.

26 S.-R. Zhang, J. Li, D.-Y. Du, J.-S. Qin, S.-L. Li, W.-W. He, Z.-M. Su and Y.-Q. Lan, J. Mater. Chem. A, 2015, 3, 2342623434.

27 (a) G. M. Sheldrick, SHELXS-97, Programs for X-ray Crystal Structure Solution, University of Göttingen: Göttingen, Germany, 1997; (b) G. M. Sheldrick, SHELXL-97, Programs for X-ray Crystal Structure Refinement, University of Göttingen: Göttingen, Germany, 1997; (c) L. J. Farrugia, WINGX, A Windows Program for Crystal Structure Analysis, University of Glasgow, Glasgow, UK, 1988.

28 V. A. Blatov, A. P. Shevchenko and D. M. Proserpio, Cryst. Growth Des., 2014, 14, 3576-3586.

29 M. Xue, G. Zhu, Y. Li, X. Zhao, Z. Jin, E. Kang and S. Qiu, Cryst. Growth Des., 2008, 8, 2478-2483.

30 (a) P. van der Sluis and A. L. Spek, Acta Crystallogr., Sect. A: Found. Crystallogr., 1990, 46, 194; (b) A. L. Spek, PLATON, Utrecht University, The Netherlands, 2001.

31 G. Massasso, J. Long, J. Haines, S. Devautour-Vinot, G. Maurin, A. Grandjean, B. Onida, B. Donnadieu, J. Larionova, C. Guérin and Y. Guari, Inorg. Chem., 2014, 53, 4269-4271.

32 W.-W. He, S.-L. Li, G.-S. Yang, Y.-Q. Lan, Z.-M. Su and Q. Fu, Chem. Commun., 2012, 48, 10001-10003.

33 H. J. Choi and M. P. Suh, J. Am. Chem. Soc., 2004, 126, 1584415851.

34 M.-H. Zeng, Q.-X. Wang, Y.-X. Tan, S. Hu, H.-X. Zhao, L.-S. Long and M. Kurmoo, J. Am. Chem. Soc., 2010, 132, 2561-2563.

35 M. S. Deshmukh, A. Chaudhary, P. N. Zolotarev and R. Boomishankar, Inorg. Chem., 2017, 56, 11762-11767.
36 Z. Yin, Q.-X. Wang and M.-H. Zeng, J. Am. Chem. Soc., 2012, 134, 4857-4863.

37 Z.-Q. Jiang, F. Wang and J. Zhang, Inorg. Chem., 2016, 55, 13035-13038.

38 Q.-K. Liu, J.-P. Ma and Y.-B. Dong, Chem. Commun., 2011, 47, 7185-7187.

39 P. Shen, W.-W. He, D.-Y. Du, H.-L. Jiang, S.-L. Li, Z.-L. Lang, Z.-M. Su, Q. Fu and Y.-Q. Lan, Chem. Sci., 2014, 5, 1368-1374.

40 M. Arici, O. Z. Yeşilel, M. Taş and H. Demiral, Cryst. Growth Des., 2017, 17, 2654-2659.

41 Z.-J. Zhang, W. Shi, Z. Niu, H.-H. Li, B. Zhao, P. Cheng, D.-Z. Liao and S.-P. Yan, Chem. Commun., 2011, 47, 64256427.

42 J.-P. Ma, Y. Yu and Y.-B. Dong, Chem. Commun., 2012, 48, 2946-2948.

43 L. Chen, K. Tan, Y.-Q. Lan, S.-L. Li, K.-Z. Shao and Z.-M. Su, Chem. Commun., 2012, 48, 5919-5921.

44 (a) G. Li, C. Yao, J. Wang and Y. Xu, Sci. Rep., 2017, 7, 13972; (b) P. Arab, M. G. Rabbani, A. K. Sekizkardes, T. İsllamoğlu and H. M. El-Kaderi, Chem. Mater., 2014, 26, 1385-1392.

45 R. J. Marshall, S. L. Griffin, C. Wilson and R. S. Forgan, Chem.-Eur. J., 2016, 22, 4870-4877.

46 Z. Wang, Y. Zhang, T. Liu, M. Kurmoo and S. Gao, Adv. Funct. Mater., 2007, 17, 1523-1536.

47 Y. Rachuri, K. K. Bisht and E. Suresh, Cryst. Growth Des., 2014, 14, 3300-3308.

48 L. Dobrzańska, G. O. Lloyd, H. G. Raubenheimer and L. J. Barbour, J. Am. Chem. Soc., 2006, 128, 698-699.

49 B. F. Abrahams, M. Moylan, S. D. Orchard and R. Robson, Angew. Chem., Int. Ed., 2003, 42, 1848-1851.

50 N.-X. Zhu, C.-W. Zhao, J.-C. Wang, Y.-A. Li and Y.-B. Dong, Chem. Commun., 2016, 52, 12702-12705.

51 Q. Zhang, F. Liu, K. T. Nguyen, X. Ma, X. Wang, B. Xing and Y. Zhao, Adv. Funct. Mater., 2012, 22, 5144-5156.

52 (a) M. Du, X. Wang, M. Chen, C.-P. Li, J.-Y. Tian, Z.-W. Wang and C.-S. Liu, Chem.-Eur. J., 2015, 21, 9713-9719; (b) E. Haque, V. Lo, A. I. Minett, A. T. Harris and T. L. Church, J. Mater. Chem. A, 2014, 2, 193-203.

53 P.-Z. Li, J. Su, J. Liang, J. Liu, Y. Zhang, H. Chen and Y. Zhao, Chem. Commun., 2017, 53, 3434-3437. 